\title{
Potential Role of Curcumin for the Treatment of Major Depressive Disorder
}

\author{
Adrian L. Lopresti ${ }^{1,2}$ (I) \\ Accepted: 16 January 2022 / Published online: 7 February 2022 \\ (c) The Author(s) 2022
}

\begin{abstract}
Curcumin is the major biologically active polyphenolic constituent in the turmeric plant (Curcuma longa) that has been shown to have antioxidant, anti-inflammatory, neuroprotective, anticancer, antimicrobial, and cardioprotective effects. Interest in curcumin as a treatment for mental health conditions has increased and there is an expanding body of preclinical and clinical research examining its antidepressant and anxiolytic effects. In this narrative review, human trials investigating the effects of curcumin for the treatment of depression or depressive symptoms are summarised. Using findings from in vitro, animal, and human trials, possible biological mechanisms associated with the antidepressant effects of curcumin are also explored. To increase the understanding of curcumin for the treatment of depression, directions for future research are proposed.
\end{abstract}

\section{Key Points}

Evidence from animal and human trials confirms curcumin is a promising treatment for depression.

Curcumin has multiple biological actions that may account for its antidepressant effects.

More research is required to increase the understanding of the antidepressant effects of curcumin.

\section{Introduction}

Curcumin, found primarily in roots and rhizomes of the turmeric plant (Curcuma longa), is the major biologically active polyphenolic constituent in turmeric. In addition to curcumin, other curcuminoids, such as demethoxycurcumin, bisdemethoxycurcumin, and cyclocurcumin, are also found

Adrian L. Lopresti

adrian@clinicalresearch.com.au

1 Clinical Research Australia, 38 Arnisdale Rd, Duncraig, Perth, WA 6023, Australia

2 College of Science, Health, Engineering and Education, Murdoch University, Perth, WA 6150, Australia in turmeric, albeit at lower concentrations. Collectively, these curcuminoids make up 2-4\% of dry turmeric root powder [1,2]. Curcuminoids are phenolic compounds commonly used as a spice, pigment, and food additive; however, cell culture and animal studies have demonstrated that curcuminoids, and in particular curcumin, have extensive biological activity, including antioxidant, anti-inflammatory, neuroprotective, anticancer, antimicrobial, and cardioprotective effects $[3,4]$.

Turmeric has traditionally been used in Indian folk medicine to treat eye infections, skin wounds, respiratory conditions and digestive complaints, and to reduce general inflammation [5, 6]. More recently, interest in curcumin as a treatment for depression has increased and there is an expanding body of research confirming antidepressant and anxiolytic effects from its administration. The aims of this narrative review are to summarise animal and clinical trials examining the antidepressant effects of curcumin and to explore possible mechanisms associated with its antidepressant effects. Directions for future research are also provided to advance the understanding of the use of curcumin for the treatment of depression. 


\section{Animal Trials Examining the Antidepressant Effects of Curcumin}

A comprehensive summary of animal trials examining the antidepressant and anxiolytic effects of curcumin was published by Lopresti [7]. In brief, animal trials have comprised acute stress exposures such as the forced swimming test, tail suspension test, sleep deprivation, immobilisation-induced restraint stress, and cold-restraint stress. Chronic stress exposure has comprised chronic unpredictable stress models (CUMS), restraint stress for periods ranging from 20 to 56 days, and the acute or chronic administration of anxiety or depressive-inducing exogenous agents such as corticosterone, pentylenetetrazole ( $\gamma$-aminobutyrate antagonist), reserpine (monoamine antagonist), 4-aminopyridine (potassium channel blocker), lead, mercuric chloride, and lipopolysaccharide (the major component of the outer membrane of Gram-negative bacteria). Surgical procedures such as ovariectomy, bilateral olfactory bulbectomy and ligation of sciatic nerves have also been used to examine the effects of curcumin on stress, depression and anxiety induced by these procedures. A selection of animal studies using the various methods to analyse the antidepressant effects of curcumin is detailed in Table 1. In most of these trials, curcumin was administered orally or via an intraperitoneal injection from 21 days to 30 min before the stressor. When curcumin was administered before the stressor, antidepressant and anxiolytic effects in animals were commonly observed, as measured by changes in behaviour, appetite, socialisation, and weight loss [8-14].

Surprisingly, there is a lack of animal studies examining the antidepressant and anxiolytic efficacy of curcumin when it is administered after a stressor. Curcumin delivered for 5 weeks after rats were subjected to CUMS for 4 weeks reversed CUMS-induced reductions in sucrose intake and elevations in corticosterone [15]. Curcumin delivered for 2 days after the administration of reserpine (a monoamine antagonist designed to induce pain and depressive behaviour) [16], 15 days after pentylenetetrazole exposure [17], and 14-21 days after surgical procedures to induce anxious or depressive behaviour [18, 19] have also resulted in antidepressant and anxiolytic effects. In animal studies designed to cause post-traumatic stress disorder, the intraperitoneal administration of curcumin for 14 days after stress exposure reduced anxiety-related behaviours in mice [20]. Furthermore, a diet enriched with curcumin consumed either before or after fear conditioning was capable of impairing fear memory consolidation and reconsolidation processes in animals [21]. In the study by Aubry et al. [22], a diet enriched with curcumin delivered 5 days before and during exposure to 10 days of chronic social defeat stress (CSDS) in mice prevented the development of social avoidance,

Table 1 A summary of methods used in animal studies to examine the antidepressant effects of curcumin

\begin{tabular}{|c|c|}
\hline \multicolumn{2}{|l|}{ Exposure to stress-inducing procedures } \\
\hline Chronic restraint stress & {$[10-12,15,23-29]$} \\
\hline Forced swimming and/or tail suspension tests & {$[30-36]$} \\
\hline Cold-restraint stress & {$[37,38]$} \\
\hline Single stress exposure & {$[20,39]$} \\
\hline \multicolumn{2}{|l|}{ Exposure to pain-inducing procedures } \\
\hline Reserpine exposure & {$[16,40]$} \\
\hline Chronic constriction injury induced by the ligation of sciatic nerves & [19] \\
\hline Trigeminal neuralgia induced by cobra venom & [41] \\
\hline \multicolumn{2}{|l|}{ Exposure to depression-inducing and neurotoxic agents } \\
\hline Corticosterone & {$[42-45]$} \\
\hline Lipopolysaccharide & {$[9,46-48]$} \\
\hline Mercury chloride & {$[8,49]$} \\
\hline Glutamate & [50] \\
\hline Rotenone & {$[51]$} \\
\hline Tetrabenazine & {$[52]$} \\
\hline Cisplatin & [53] \\
\hline Pentylenetetrazole & [17] \\
\hline Amyloid- $\beta$ peptide & {$[54]$} \\
\hline \multicolumn{2}{|l|}{ Exposure to surgical procedures } \\
\hline Ovariectomy & {$[24,55]$} \\
\hline Olfactory bulbectomy & {$[56-58]$} \\
\hline
\end{tabular}


attenuated stress-induced increases in peripheral and central interleukin (IL)-6 and blocked stress-induced increases in hypothalamus-pituitary-adrenal (HPA) axis activity. However, when curcumin was delivered after exposure to CSDS for 3 weeks, it did not reverse the stress-induced behavioural changes in the mice. These results suggest that curcumin may be best delivered before or during stress exposure to have significant effects on depressive or anxious behaviours. These findings could have significant implications on how curcumin is administered in clinical trials and clinical practice, as it is usually administered after the onset of depressive symptoms or stress exposure.

\section{Human Trials Examining the Antidepressant Effects of Curcumin}

Studies were identified using the Medline (Pubmed), Cochrane Library, Scopus, Web of Science, and CINAHL databases, and by examining reference lists of relevant papers to locate additional studies that were not identified by the database searches. Databases were scanned from all years of study until October 2021. A systematic search of human trials using the terms (curcumin or turmeric or curcuminoids) and (treatment or trial or intervention or study or clinical) was completed. Specific inclusion criteria for the human trials included the following: (1) published in English; (2) adult human interventional trial (randomised controlled, non-randomised, and open-label) assessing the effects of curcumin or turmeric on depression or affective symptoms; (3) completed pre- and post-intervention outcome measures; and (4) used curcumin or turmeric as a stand-alone or adjunct intervention.

\subsection{Adults with Depression}

As detailed in Table 2, seven trials have examined the effects of curcumin in adults with clinical depression. Treatments lasted 5-12 weeks, with daily dosages ranging from 500 to $1500 \mathrm{mg}$. Varying curcumin extracts have been utilised in these trials, including non-patented [59-61] and patented extracts such as BCM-95 ${ }^{\circledR}[62,63]$ and $\mathrm{C} 3$ Complex $^{\circledR}$ [64]. Curcumin was administered as a stand-alone treatment in three trials $[62,65,66]$ and as an adjunct to pharmaceutical antidepressants in four trials [59-61, 63]. Positive antidepressant effects were reported in six of the seven trials, with the only non-significant finding identified by Bergman et al. [59], where curcumin was used as an adjunct to pharmaceutical antidepressants and administered for the shortest treatment period of all the trials (5 weeks). Positive anxiolytic effects from curcumin administration were also identified in four trials $[62,64,65,67]$. In a recent meta-analysis based on the results from six randomised, double-blind, placebo-controlled trials on people with depression, an effect size of 0.35 compared with placebo administration was identified [68]. Based on the results of a meta-analysis of nine randomised-controlled studies (two on non-depressed populations), a larger effect size of 0.75 compared with placebo was reported by Fusar-Poli and colleagues [69]. Interestingly, in this meta-analysis, an even larger treatment effect was identified when examining the effects of curcumin on anxiety symptoms (Hedge's $g=2.62$ ). In a meta-analysis conducted in 2016 [70], it was concluded from subgroup analyses that curcumin had the highest antidepressant effects when administered to middle-aged adults, for longer treatment periods, and at higher doses. However, with the addition of more recent publications, these conclusions, along with an exploration of the effects of cultural influences and different curcumin extracts on antidepressant outcomes, will be important.

\subsection{Non-Depressed Populations}

As detailed in Table 2, the effects of curcumin on mood in non-depressed populations have been investigated in eight trials. This has included an examination into its moodenhancing effects in healthy, older-age adults [71], overweight or obese adults [72-74], women with premenstrual syndrome [75], adults with type 2 diabetes [76], adults with self-reported digestive complaints [77], and adults with pulmonary hypertension [78]. Treatment dosages ranged from 80 to $2000 \mathrm{mg} /$ day utilising varying curcumin extracts, with treatment periods ranging from a single dose to 4 months. When a change in depressive symptoms was investigated, depressive symptoms were significantly reduced in two of seven trials [76, 78]. Anxiolytic effects were identified in five of seven trials [72, 74, 76-78] that measured changes in anxiety. In a meta-analysis by Wang and colleagues [68], when the antidepressant effects of curcumin were examined in non-depressed populations, an effect size of 0.32 was identified.

\section{Curcumin's Potential Antidepressant Mechanisms of Action}

Depression is associated with a range of biological disturbances that may cause or contribute to its array of behavioural, affective, cognitive and physical symptoms. As detailed in Fig. 1, findings from in vitro, animal and human studies have demonstrated that curcumin has multifactorial physiological effects on the body, which may account for its antidepressant and anxiolytic effects. 


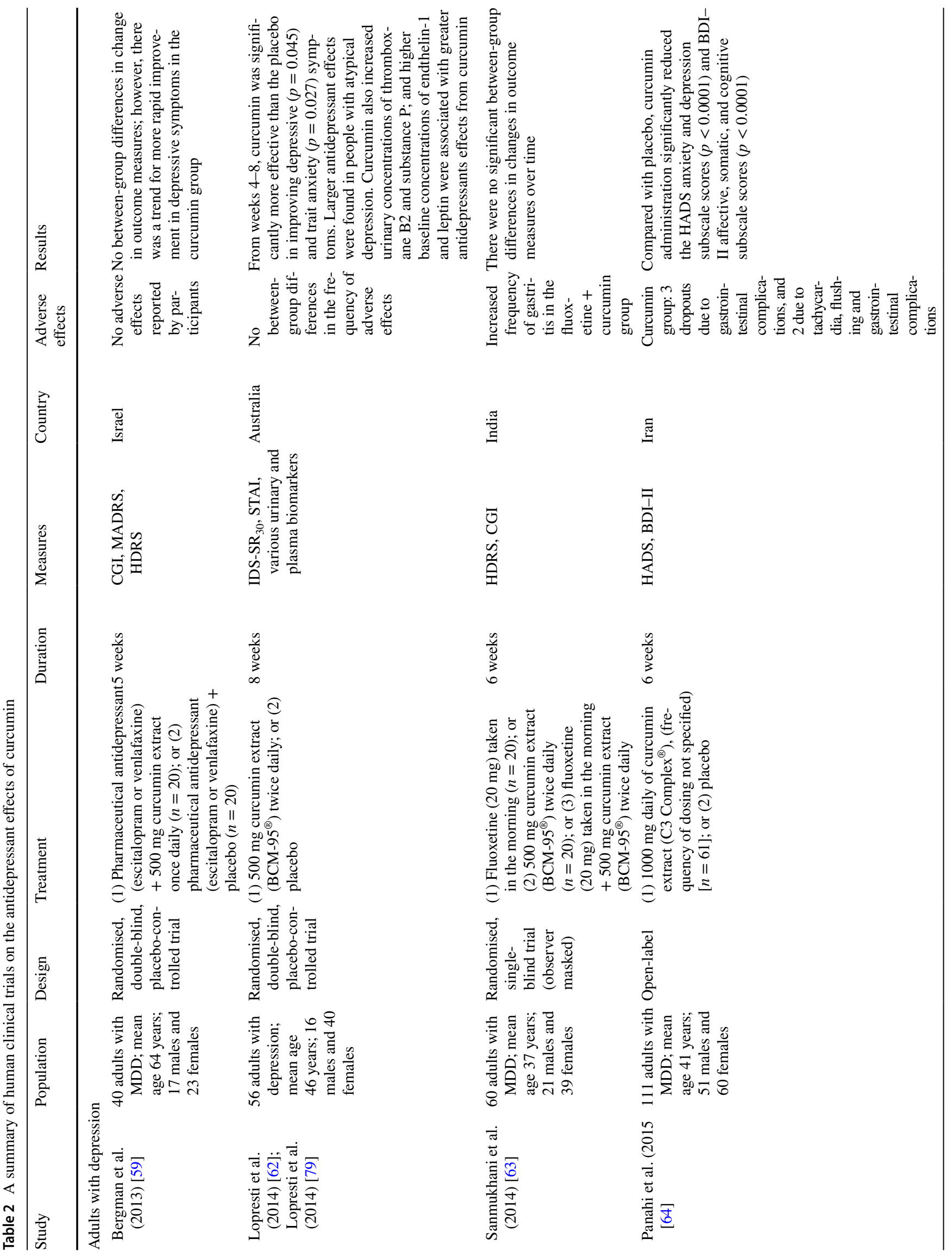




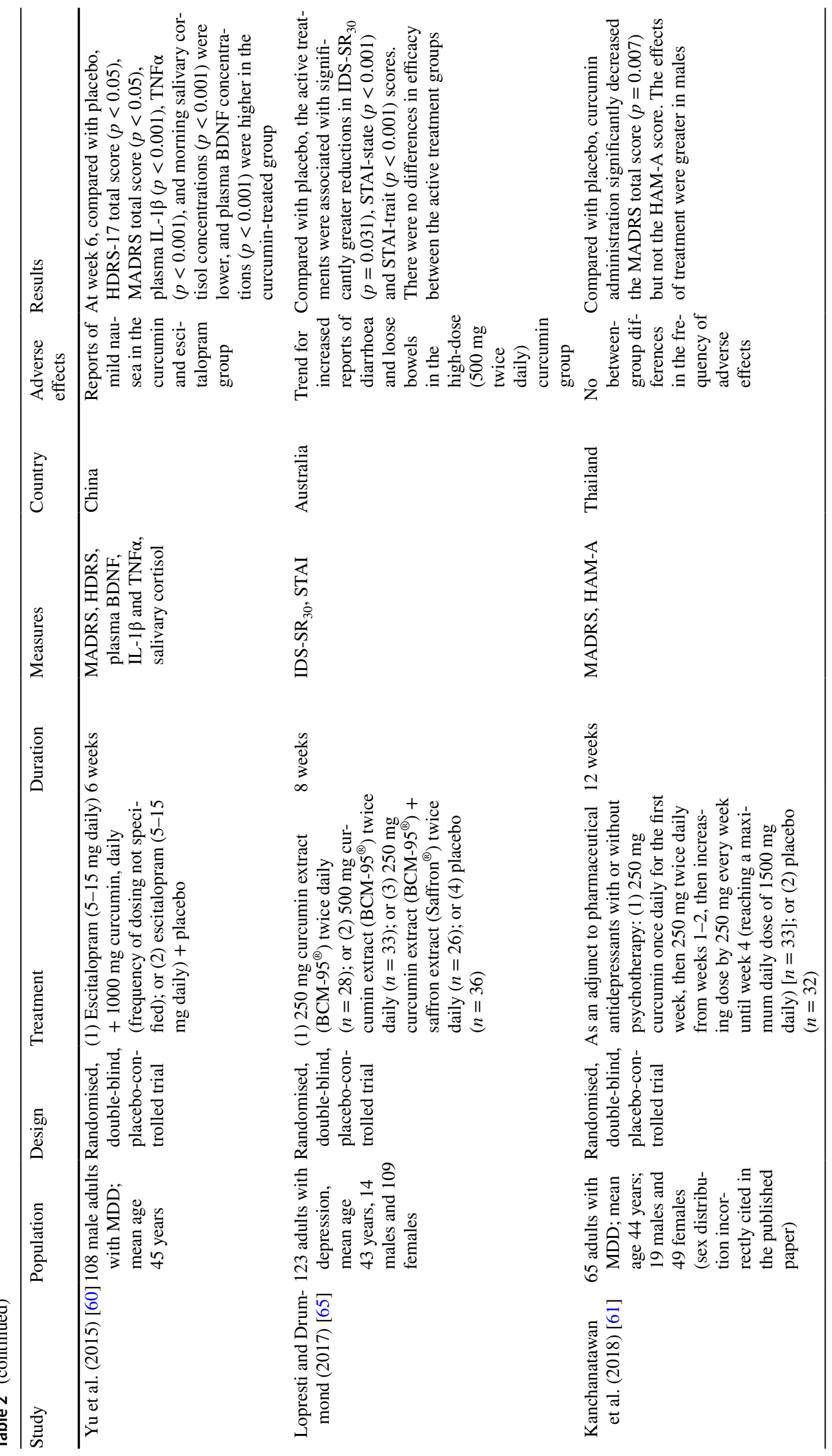




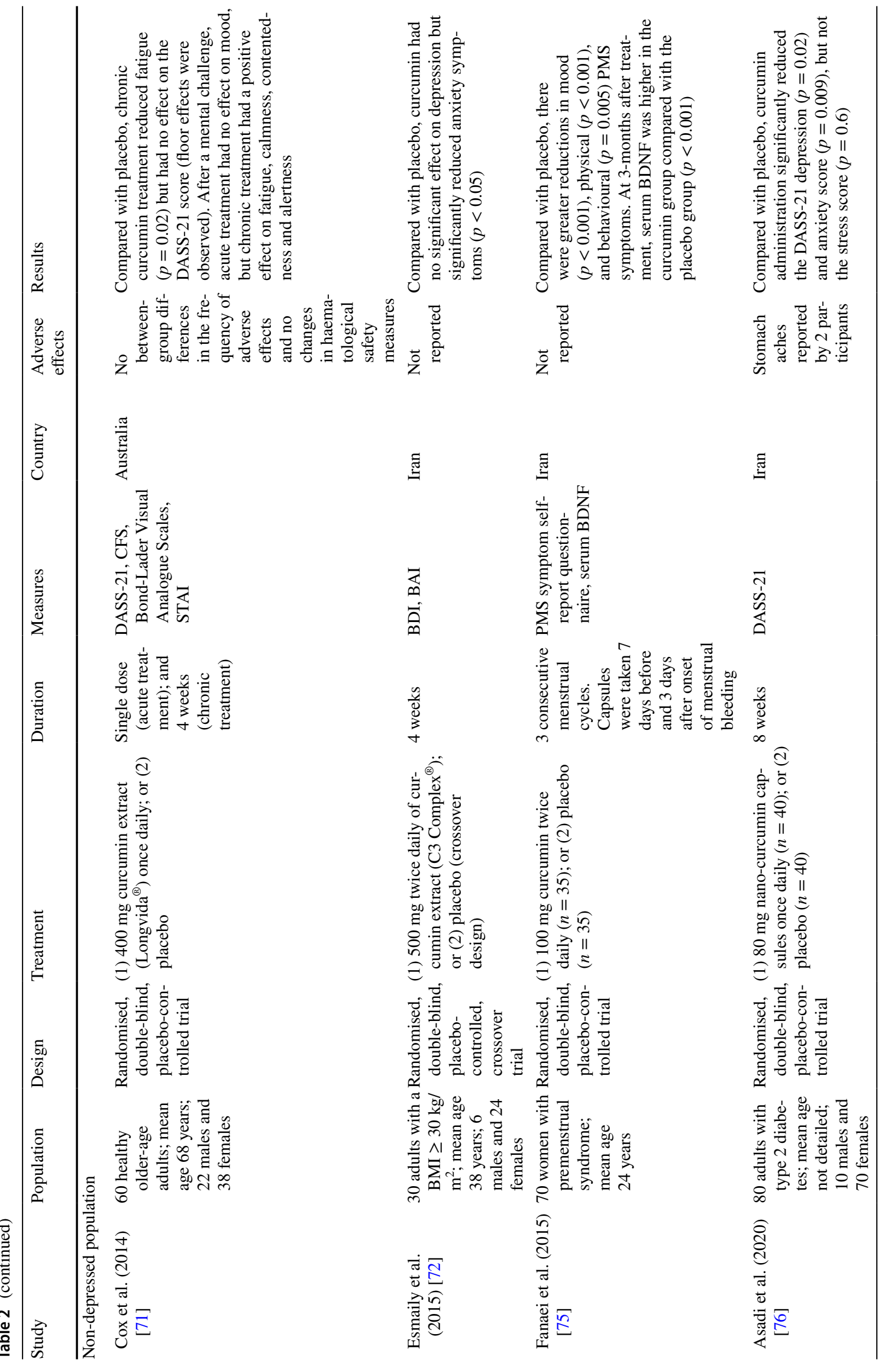




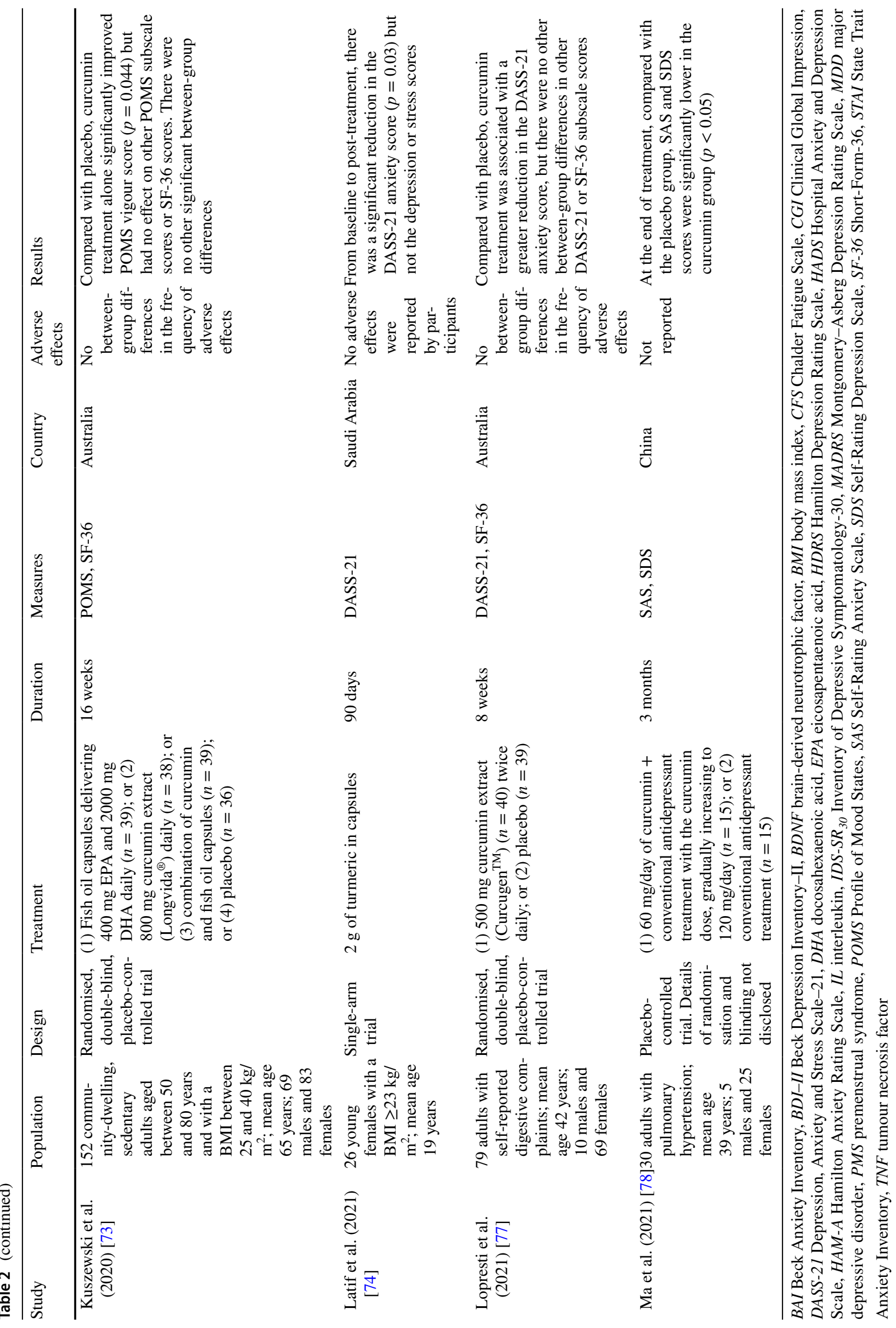


Fig. 1 Potential pathophysiological processes in depression restored by curcumin. GI gastrointestinal, $B B B$ blood-brain barrier, HPA hypothalamuspituitary-adrenal, DHA docosahexaenoic acid

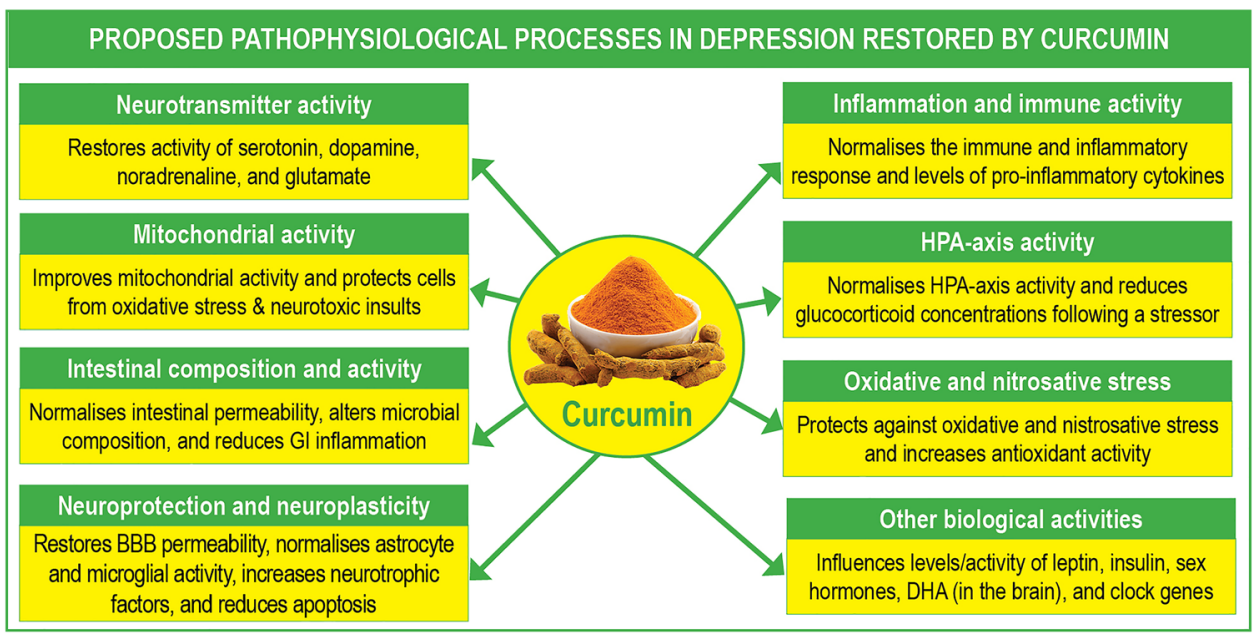

\subsection{Neurotransmitter Activity}

Disturbances in neurotransmitter activity involving serotonin (5-HT), dopamine, noradrenaline [80] and glutamate [81] have been regularly observed in depression. Findings from animal trials have demonstrated curcumin can alter the concentrations and activity of many of these neurotransmitters. For example, the acute administration of curcumin ameliorated depression-like behaviour in mice through its stimulatory influence on the 5- $\mathrm{HT}_{1 \mathrm{~A}}$ receptor [30]. In ovariectomised mice, curcumin modulated depression-like behaviours and improved the serotonin content in several brain regions by upregulating tryptophan hydroxylase- 2 and 5- $\mathrm{HT}_{1 \mathrm{~A} / 2 \mathrm{~A}}$ receptor messenger RNA (mRNA) and downregulating monoamine oxidase A mRNA in the limbic system [13]. In rats exposed to single, prolonged stress, curcumin reduced anxiolytic behaviours and restored stress-induced decreases of 5-HT tissue concentrations in the hippocampus, amygdala and striatum [20]. Curcumin has also been shown to modulate dopamine and noradrenaline concentrations in several brain regions in ovariectomised rats [55], reduced diabetes-induced alterations of the dopamine D1 and D2 receptors [82] and ameliorated rotenone-induced dopamine depletion [83]. Rotenone is a commonly used pesticide that causes a depletion of dopamine in the brain [84]. There is also evidence that curcumin can protect against glutamateinduced neurotoxicity by influencing $N$-methyl-D-aspartate (NMDA) receptor activity by increasing GluN2A subunit expression and facilitating the phosphorylation of $\alpha$-amino3-hydroxy-5-methyl-4-isoxazolepropionic acid (AMPA) receptor subunit GluR1 [85-88].

\subsection{Inflammation}

A relationship between inflammation and depression is becoming increasingly recognised. Based on several meta-analyses, adults with depression exhibit higher concentrations of proinflammatory markers such as C-reactive protein (CRP), IL-6, and tumour necrosis factor (TNF)- $\alpha$ [89-91]. Moreover, approximately one-quarter of patients with depression show evidence of low-grade inflammation, and over half of patients show mildly elevated CRP levels [91]. Dysregulation in the kynurenine pathway, which is induced by inflammation and in turn fuels inflammation and neurotoxicity, has also been implicated in the pathophysiology of depression [92]. Higher inflammation, demonstrated by elevated concentrations of CRP is also observed in suicidal patients with depression compared with non-suicidal depressed patients [93]. Despite the commonly held belief that pharmaceutical antidepressants target neurotransmitter activity, it is becoming increasingly recognised that they also have anti-inflammatory actions that may at least partly account for their therapeutic activity [94, 95]. In a meta-analysis on antidepressant trials, it was concluded that alterations in peripheral cytokine levels were associated with antidepressant treatment outcomes in major depressive disorder [95].

The anti-inflammatory effects of curcumin have been demonstrated in both animal and human trials. Based on a meta-analysis of 32 human trials, it was confirmed that curcumin lowered concentrations of CRP and high-sensitivity CRP [95]. In another meta-analysis of 15 randomised controlled trials, it was concluded that curcumin supplementation significantly decreased IL-6 and high-sensitivity CRP, but no significant effect on TNF- $\alpha$ was identified [96]. In animal stress and depression models, curcumin administration delivered before CUMS significantly alleviated depression-like behaviours and the expression of the proinflammatory cytokine IL-1 $\beta$ [24]; inhibited cytokine gene expression (TNF $\alpha$ and IL-6) at both the mRNA and the protein level and reduced the activation of Nuclear factor- $\kappa \mathrm{B}(\mathrm{NF}-\kappa \mathrm{B})$ [97]; and decreased mRNA expression of proinflammatory 
cytokines IL-1 $\beta$, IL-6, and TNF $\alpha$, suppressed NF- $\kappa B$ activation, and inhibited the stressed-induced NLRP3 inflammasome axis activation, along with reducing the transformation of pro-IL- $1 \beta$ into mature IL- $1 \beta$. The stress-induced activation of indolamine-2, 3-dioxygenase, and an increased kynurenine/tryptophan ratio were also ameliorated by curcumin supplementation [25]. Moreover, lipopolysaccharide exposure in mice induced anxiety and depressive-like behaviours and neurochemical changes in the hippocampus, however pretreatment with curcumin significantly reduced concentrations in the proinflammatory cytokines IL- $1 \beta$ and $\mathrm{TNF} \alpha$ [46]. In a placebo-controlled human depression trial, as an adjunct to antidepressants, curcumin decreased inflammatory cytokines IL-1 $\beta$ and TNF $\alpha$ concentrations [60].

\subsection{Oxidative and Nitrosative Stress}

Increased oxidative and nitrosative stress has been regularly identified in depression. This is demonstrated by lower levels of enzymatic and non-enzymatic antioxidants; increased concentrations of oxidative and nitrosative stress markers such as malondialdehyde, protein carbonyls, thiols, and nitrotyrosines; and altered activity of nitric oxide synthase and nitric oxide production $[98,99]$. As an antioxidant, curcumin can lower levels of malondialdehyde, protein carbonyls, thiols, and nitrotyrosines; increase the activity of antioxidant enzymes such as superoxide dismutase, catalase, and glutathione peroxidase; increase reactive oxygen species and reactive nitrogen species scavenging activity; and protect against the overproduction of nitric oxide [47, 100-102]. In animal stress models, curcumin has protected against increases in oxidative stress by lowing malondialdehyde and protein carbonyl concentrations, and increased the activity of antioxidant enzymes such as superoxide dismutase, catalase, and glutathione peroxidase [10, 38, 39, 55]. Human trials have also confirmed curcumin's antioxidant effects via reductions in malondialdehyde in adults with non-alcoholic fatty liver disease [103] and moderately physically active females [104]. Moreover, increased catalase activity in haemodialysis patients [105] and total antioxidant capacity and glutathione levels in adults with type 2 diabetes and coronary heart disease [106] have been observed. In a meta-analysis based on four studies and 308 participants, it was confirmed that curcumin significantly increased total antioxidant capacity and had a tendency to decrease malondialdehyde concentrations [107].

\subsection{Hypothalamus-Pituitary-Adrenal Axis Activity}

The HPA axis plays a central role in the stress response and, via the release of glucocorticoids (cortisol in humans and corticosterone in rodents), regulates many essential physiological processes. It is estimated that $40-60 \%$ of patients with depression experience hypercortisolemia or other HPAaxis disturbances, such as a flattened circadian state rhythm or an earlier or elevated nadir. Elevated HPA axis activity has been identified in depression subtypes such as melancholic depression and depression with psychotic features [108-110]. There have been several animal trials that have confirmed curcumin can lower corticosterone concentrations in mice and rats exposed to various animal stress and depression models. These include after chronic exposure to restraint stress [23], social defeat stress [22], unpredictable mild stress [14], and exposure to mercury chloride [49]. Corticosterone-lowering effects from curcumin may occur via its ability to inhibit adrenocorticotropic hormone secretion [111], its influence on 11ß-hydroxysteroid dehydrogenase activity (an enzyme involved in the interconversion of cortisol and cortisone) [112-114] and/or glucocorticoid receptor sensitivity and expression in the brain [26, 115]. In human trials, as an adjunct to antidepressants, curcumin lowered salivary cortisol concentrations compared with placebo [60]; however, in another placebo-controlled trial on adults with depression, it had no significant effect on salivary cortisol concentrations [116]. In a placebo-controlled trial on adults with non-alcoholic fatty liver disease, reductions in serum cortisol were identified after 8 weeks of curcumin supplementation [117].

\subsection{Neuroprotection and Neuroplasticity}

\subsubsection{Blood-Brain Permeability}

The blood-brain barrier (BBB) acts as a highly regulated interface that shields the brain from toxic substances in the blood, supplies brain tissues with nutrients, and filters harmful compounds from the brain back to the bloodstream [118]. Alterations in the BBB can lead to increased infiltration of peripheral material into the brain, culminating in neuroinflammation and oxidative stress. Perturbations in BBB regulation may contribute to the development of psychiatric disorders, including depression [119-121]. In vitro and animal studies have demonstrated that curcumin can protect the integrity of the BBB after ischemic stroke injury [122], cerebral ischemia-reperfusion injury [123], subarachnoid haemorrhage [124], and hypoxia [125].

\subsubsection{Neurotrophins}

Neurotrophins such as brain-derived neurotrophic factor (BDNF) and nerve growth factor are a family of proteins that support the survival, development and function of neurons [126]. The neurotrophic hypothesis of depression proposes that abnormalities in neurotrophin concentrations lead to neuronal atrophy and decreased neurogenesis, resulting in mood disorders. This theory is supported by findings 
of lowered concentrations of serum and plasma BDNF in patients with depression and the ability of many pharmaceutical antidepressants to increase BDNF concentrations [127, 128]. Results from animal stress models have confirmed curcumin can increase concentrations of BDNF [23, $29,34,129,130]$. Increases in peripheral BDNF have also been identified in several human trials. In a meta-analysis of four human randomised control trials comprising 139 participants, curcumin supplementation for 8-12 weeks significantly increased serum BDNF levels [131]. In a randomised, double-blind, placebo-controlled trial of adults with depression, the adjunct administration of curcumin with pharmaceutical antidepressants for 6 weeks was associated with greater increases in serum BDNF compared with placebo [60].

\subsubsection{Neuroinflammation}

Astrocytes are the most abundant glial cells in the central nervous system (CNS) and are responsible for a wide variety of complex and essential functions in a healthy CNS, including having roles in synaptic transmission, the preservation of brain homeostasis, trophic support, and the modulation of neuronal circuits [132]. Disturbances in astrocytic function are involved in the pathogenesis of neurodegenerative diseases and can contribute to an overactive inflammatory/ immune response in the CNS. Evidence from post-mortem human brain tissues has demonstrated changes in glial cell morphology, density, and astrocyte-related biomarkers and genes in mood disorders [133]. It has also been observed that multiple brain regions in individuals with depression have reduced astrocyte densities [134]. An increasing number of studies have confirmed that curcumin is capable of directly inhibiting activated astrocyte activity, inflammation in astrocytes, and significantly increasing astrocyte survival after oxidative stress [135-138].

Microglia are another type of glial cell that make up the innate immune system of the CNS and are key cellular mediators of neuroinflammatory processes [139]. In addition to releasing inflammatory mediators, microglia can also secrete glutamate and metabolise kynurenine transported to the CNS into quinolinic acid, a neurotoxic compound [140]. Studies have revealed overactive microglia in patients with depression, with even greater activity in suicidal patients [141]. Studies have suggested that during stress and pathologies, microglia play a significant role in disrupting neuroplasticity and have detrimental effects on neuroprotection, causing neuroinflammation and an exacerbation of depression [139]. Curcumin can inhibit microglia transformation and associated inflammatory mediators such as IL- $1 \beta$ and TNF $\alpha$, and mitigates neuroinflammation by modulating microglia polarisation [47, 100, 142, 143]. Curcumin administration also has protective effects against quinolinic acid-induced neurotoxicity $[144,145]$.

\subsection{Mitochondrial Activity}

Mitochondria are cellular organelles involved in energy production and several other biological processes, such as regulating oxidative stress and apoptosis. A relationship between mitochondrial dysfunction, characterised by impairments in energy production and increased oxidative stress and depression, has been reported in a wide range of studies on cell cultures, animal models, and clinical research [146-149]. Consequently, interest in treatments that target mitochondria dysfunction is on the rise. Findings from in vitro and in vivo studies have indicated curcumin can protect neuronal cells against mitochondrial pathology in a wide range of neurodegenerative-inducing stressors such as cerebral ischemia, and exposure to neurotoxic compounds such as methamphetamine, alcohol, rotenone, hydrogen peroxide, glutamate, interferon- $\gamma$ and aluminium [150-155]. It has been reported that curcumin exerts its mitochondria protecting properties by retaining the activities of mitochondrial electron transport chain complexes and $\mathrm{Bax} / \mathrm{Bcl}-2$ ratio; enhancing mitochondrial fusion activity, mitochondrial biogenesis, and synaptic proteins; reducing fission machinery and mitochondrial swelling; reducing lipid peroxidation, protein carbonylation, and levels of oxidised lipids in the brain; reducing apoptosis, cytochrome c, caspase- 3 and -9 activation, and mitochondrial depolarisation; reducing concentrations of TNF $\alpha$, IL-1 $\beta$ and other inflammatory cytokines; modulating phosphoCREB-BDNF signalling and nuclear factor-erythroid factor 2-related factor 2; and restoring glutathione levels and superoxide dismutase activity $[150,156]$.

\subsection{Intestinal Microbiota and Permeability}

The gut-brain axis (GBA) refers to a bidirectional communication between the gastrointestinal tract and the CNS involving the neural, endocrine, and immune pathways. Disturbances in the GBA have been identified in depression, including changes in the composition of intestinal microbiota and increased intestinal hyperpermeability $[157,158]$. Because processes within the GBA can influence HPA-axis activity, neurotransmitter production, BDNF production, and the immune response, it is increasingly recognised as a target of intervention for the treatment and prevention of depression $[159,160]$. Despite curcumin having low oral bioavailability, therapeutic effects from curcumin have been observed in a wide array of conditions. It has been postulated that curcumin's benefits may be derived via its effect on the gastrointestinal system; namely, its influence on intestinal microbiota, intestinal permeability, and gut inflammation and oxidative stress [161]. In a cell-culture model, 
tight junction redistribution and an increased inflammatory response was ameliorated by curcumin after exposure to Campylobacter jejuni (a common cause of foodborne gastroenteritis) [162]; and in mice exposed to a high-fat diet, curcumin upregulated the expression of intestinal tight junction proteins, occludin and zonula occluden-1 [163]. Moreover, in a human trial, 3 days of curcumin supplementation reduced gastrointestinal barrier damage during exertional heat stress in non-heat-acclimated adults [164]. There is also increasing research demonstrating curcumin can influence the composition of gut microbiota. In mice fed a highfat diet, curcumin altered gut microbiota by increasing the relative abundance of the Lactococcus, Parasutterella, and Turicibacter genera [165]. In a rat uric acid nephropathy model, curcumin treatment protected against the overgrowth of opportunistic pathogens, including Escherichia-Shigella and Bacteroides, and increased the relative abundance of bacteria producing short-chain fatty acids, such as Lactobacillus and Ruminococcaceae [166]. Moreover, in asthmainduced mice, curcumin altered the composition of gut microbiota characterised by a significant decrease in the Firmicutes to Bacteroidetes ratio and reduction in the relative abundances of proinflammatory bacteria, such as Proteobacteria, Intestinimonas, unidentified Ruminococcaceae, and Lachnospiraceae [167]. In a human trial, the number of taxa detected increased by $69 \%$ in participants consuming curcumin for 8 weeks, compared with a $7 \%$ increase and $15 \%$ decrease in participants administered turmeric or a placebo. However, in an 8-week trial in adults with selfreported digestive complaints, curcumin administration did not significantly alter the composition of gut microbiota compared with placebo [77].

\subsection{Other Biological Activities}

\subsubsection{Leptin}

Differences in concentrations of leptin have been identified in depression, comprising findings of both increased and decreased concentrations [168-171]. In a meta-analysis based on four human trials, it was confirmed that curcumin lowers plasma leptin concentrations [172]. Understanding the role of leptin in depression requires further investigation; however, curcumin's influence on leptin and possibly leptin receptor sensitivity and leptin resistance present as another potential mechanism of action.

\subsubsection{Insulin and Blood Sugar Regulation}

Disturbances in blood sugar regulation, insulin concentrations, and insulin resistance have been identified in depression [173, 174]. Although the administration of antihyperglycaemic agents, including metformin and peroxisome proliferator-activated receptor- $\gamma$ (PPAR $\gamma$ ) receptor agonists, have yielded inconsistent findings in depression studies, insulin signalling has been shown to influence serotonergic transmission [173, 174]. Based on a meta-analysis of four trials and 453 participants, it was concluded that curcumin supplementation may assist in improving insulin resistance and glycaemic control [175].

\subsubsection{The Endocannabinoid System}

The endocannabinoid system (ECS) is a neuromodulator system that has a significant influence on the CNS and the inflammatory reaction to endogenous and exogenous compounds. The ECS also influences anxiety, feeding behaviour, emotional responses, HPA-axis activity, and neurogenesis [176, 177]. Alterations in the ECS have been identified in depression and present as a therapeutic target of intervention [177, 178]. In animal trials, curcumin administration has influenced the ECS by increasing cannabinoid receptor type 1 (CB1)-mediated endocannabinoid signalling and increasing levels of CB1 mRNA [42, 179].

\subsubsection{Sex Hormones}

Even though findings are inconsistent, a relationship between sex hormones such as estrogen and testosterone and depression has been identified [180, 181]. Curcumin can influence multiple pathways associated with estrogen receptor expression and signalling [182, 183], and, in an animal study, ameliorated fluoxetine-induced reductions in testosterone [184] and influenced the activity of $17 \beta$-hydroxysteroid dehydrogenase, an enzyme involved in the biosynthesis of testosterone [185].

\subsubsection{Docosahexaenoic Acid Synthesis in the Brain}

There is an increasing body of evidence confirming a relationship between low omega-3 polyunsaturated fatty acids status and depression [186]. Docosahexaenoic acid (DHA) is the most prevalent omega-3 fatty acid in brain tissue and is critical for brain development and health [187]. In an animal study, compared with the administration of $\alpha$-linolenic (ALA) alone (a precursor to DHA), its delivery in combination with curcumin enhanced the synthesis of DHA, elevated levels of enzymes involved in the synthesis of DHA such as fatty acid desaturase 2 and elongase 2, and increased DHA concentrations in both liver and brain tissue. Furthermore, treatment with curcumin and ALA reduced anxiety-like behaviour in rodents [188]. 


\subsubsection{Clock Gene Expression}

After alterations to light/dark cycles, stress and anxiety-like behaviour were significantly increased in mice. However, the concurrent administration of curcumin ameliorated these behavioural changes and modulated the expression of the Period Circadian Regulator 1 (PERI) gene [189]. In other animal studies, age-induced alterations in the daily rhythms of clock genes were restored by curcumin administration [190, 191]. The PER1 gene and other clock genes are involved in biological processes such as feeding behaviour, sleep deprivation and vulnerability to depression [192-195].

\section{Safety and Tolerability of Curcumin}

In human trials, curcumin has been well tolerated with the frequency of self-reported adverse effects often similar to placebo administration. The most common adverse effects include mild gastrointestinal discomfort such as nausea, mild abdominal pain and diarrhea [69, 70]. A summary of adverse effects reported in depression trials are detailed in Table 2. In a search conducted in January 2022 on the US FDA website, three curcumin extracts had received approval by the FDA as 'generally recognised as safe' [196]. Moreover, good tolerability and safety profiles have been shown in clinical trials, even at doses between 4000 and $8000 \mathrm{mg} /$ day [197]. However, curcumin may increase the risk of bleeding in people taking warfarin and antiplatelet drugs, and can potentiate the effect of other medications such as antibiotics, anti-inflammatories, and chemotherapy agents, therefore some caution is warranted when used in combination with these medications $[3,198]$. Human trials examining the chronic administration of curcumin are limited; however, in preclinical systematic safety studies commissioned by the National Cancer Institute, no toxic effects were identified at doses of $3.5 \mathrm{~g} / \mathrm{kg}$ administered for 3 months to rats, dogs and monkeys [199].

\section{Conclusions and Directions for Future Research}

There is an increasing body of research supporting the efficacy of curcumin as a treatment for depression. These antidepressant effects have been demonstrated in both animal and human trials and have been confirmed by several meta-analyses [68, 69]. However, further research comprising larger sample sizes, depression subtypes and severities, and administered as a stand-alone or adjunct treatment is required. As summarised in Fig. 1, the antidepressant effects of curcumin may occur via several mechanisms; however, further investigations are needed to provide a more definitive understanding of the antidepressant processes associated with curcumin. Moreover, it will be important to understand if curcumin has greater mood-enhancing effects if administered to adults with depression presenting with biological disturbances that could be ameliorated by curcumin administration. For example, given curcumin's anti-inflammatory effects, it will be important to determine if it will have greater efficacy in people with depression presenting with elevated markers of inflammation. In the study by Lopresti et al. [62], larger treatment effects were identified in people with atypical depression, which is often accompanied by higher peripheral inflammation.

Clinical trials to date have lasted 4-16 weeks, therefore the efficacy and safety of longer-term curcumin intake require further investigation. Treatment doses have also differed substantially, and optimal treatment doses have not yet been identified. Moreover, understanding the effects of curcumin administered before or during times of stress, or delivered as a treatment for the prevention of depression in people at high risk of depression, will be helpful. This will be a valuable area of investigation, as, in most animal trials, curcumin was delivered before exposure to a stressor, and in one trial had no antidepressant/anxiolytic effects when it was delivered after stress exposure [22]. Given curcumin's anxiolytic effects in animal studies, and findings of anxiety reductions in clinical trials in depressed populations, an examination into its influence on anxiety symptoms in people presenting with anxiety disorders, experiencing high stress, and/or with comorbid depression and anxiety will be important. The anti-stress effects of curcumin in human experimental stress models such as the Maastricht Acute Stress Test or Trier Social Stress Test model may help to clarify some of the physiological mechanisms associated with curcumin [200, 201]. Finally, because of curcumin's poor oral bioavailability, various extracts have been formulated with greater bioavailability. However, despite confirmation of increased oral bioavailability, head-to-head comparisons of the antidepressant efficacy of these extracts have not been undertaken [1]. Such trials will be important to determine if different extracts impact safety, tolerability, and antidepressant outcomes. In conclusion, the results from studies to date confirm curcumin as a promising treatment for depression, but further research in this area is essential.

\section{Declarations}

Funding Open Access funding enabled and organized by CAUL and its Member Institutions. No funding was received and no funding sources were used to assist in the preparation of this manuscript.

Conflicts of interest Adrian Lopresti is the Managing Director of Clinical Research Australia, a contract research organisation. He has received research funding from nutraceutical companies for research 
into curcumin and other herbal extracts, and has also received presentation honoraria from nutraceutical companies.

Availability of data and material Not applicable.

Ethics approval Not applicable.

Consent to participate Not applicable.

Consent for publication Not applicable.

Code availability Not applicable.

Author contributions Adrian Lopresti conceptualised the format, and wrote and edited the paper in its entirety.

Open Access This article is licensed under a Creative Commons Attribution-NonCommercial 4.0 International License, which permits any non-commercial use, sharing, adaptation, distribution and reproduction in any medium or format, as long as you give appropriate credit to the original author(s) and the source, provide a link to the Creative Commons licence, and indicate if changes were made. The images or other third party material in this article are included in the article's Creative Commons licence, unless indicated otherwise in a credit line to the material. If material is not included in the article's Creative Commons licence and your intended use is not permitted by statutory regulation or exceeds the permitted use, you will need to obtain permission directly from the copyright holder. To view a copy of this licence, visit http://creativecommons.org/licenses/by-nc/4.0/.

\section{References}

1. Stohs SJ, Chen O, Ray SD, Ji J, Bucci LR, Preuss HG. Highly bioavailable forms of curcumin and promising avenues for curcumin-based research and application: a review. Molecules. 2020;25(6):1397.

2. Amalraj A, Pius A, Gopi S, Gopi S. Biological activities of curcuminoids, other biomolecules from turmeric and their derivatives—a review. J Tradit Complement Med. 2017;7(2):205-33.

3. Sharifi-Rad J, Rayess YE, Rizk AA, Sadaka C, Zgheib R, Zam $\mathrm{W}$, et al. Turmeric and its major compound curcumin on health: bioactive effects and safety profiles for food, pharmaceutical biotechnological and medicinal applications. Front Pharmacol. 2020;11:01021.

4. Ahmad RS, Hussain MB, Sultan MT, Arshad MS, Waheed M, Shariati MA, et al. Biochemistry, safety, pharmacological activities, and clinical applications of turmeric: a mechanistic review. Evid Based Complement Alternat Med. 2020;2020:7656919.

5. Hatcher H, Planalp R, Cho J, Torti FM, Torti SV. Curcumin: from ancient medicine to current clinical trials. Cell Mol Life Sci. 2008;65(11):1631-52.

6. Prasad S, Aggarwal BB. Turmeric, the golden spice: from traditional medicine to modern medicine. In: Benzie IFF, WachtelGalor S, editors. Herbal medicine: biomolecular and clinical aspects. Boca Raton: CRC Press/Taylor \& Francis; 2011.

7. Lopresti AL. Curcumin for neuropsychiatric disorders: a review of in vitro, animal and human studies. J Psychopharmacol. 2017;31(3):287-302.

8. Abu-Taweel GM, Rudayni HA. Curcumin ameliorated the mercuric chloride induced depression and anxiety in female mice offspring. Environ Res. 2021;204(Pt B):112031.
9. Rubab S, Naeem K, Rana I, Khan N, Afridi M, Ullah I, et al. Enhanced neuroprotective and antidepressant activity of curcumin-loaded nanostructured lipid carriers in lipopolysaccharide-induced depression and anxiety rat model. Int J Pharm. 2021;603:120670.

10. da Silva Marques JG, Antunes FTT, da Silva Brum LF, Pedron C, de Oliveira IB, de Barros Falco Ferraz A, et al. Adaptogenic effects of curcumin on depression induced by moderate and unpredictable chronic stress in mice. Behav Brain Res. 2021;399:113002.

11. Liao D, Lv C, Cao L, Yao D, Wu Y, Long M, et al. Curcumin attenuates chronic unpredictable mild stress-induced depressivelike behaviors via restoring changes in oxidative stress and the activation of Nrf2 signaling pathway in rats. Oxid Med Cell Longev. 2020;2020:9268083.

12. Naqvi F, Saleem S, Naqvi F, Batool Z, Sadir S, Tabassum S, et al. Curcumin lessens unpredictable chronic mild stressinduced depression and memory deficits by modulating oxidative stress and cholinergic activity. Pak J Pharm Sci. 2019;32(4 Suppl):1893-900.

13. Abd-Rabo MM, Georgy GS, Saied NM, Hassan WA. Involvement of the serotonergic system and neuroplasticity in the antidepressant effect of curcumin in ovariectomized rats: comparison with oestradiol and fluoxetine. Phytother Res. 2019;33(2):387-96.

14. Shen JD, Wei Y, Li YJ, Qiao JY, Li YC. Curcumin reverses the depressive-like behavior and insulin resistance induced by chronic mild stress. Metab Brain Dis. 2017;32(4):1163-72.

15. Li YC, Wang FM, Pan Y, Qiang LQ, Cheng G, Zhang WY, et al. Antidepressant-like effects of curcumin on serotonergic receptor-coupled AC-cAMP pathway in chronic unpredictable mild stress of rats. Prog Neuropsychopharmacol Biol Psychiatry. 2009;33(3):435-49.

16. Arora V, Kuhad A, Tiwari V, Chopra K. Curcumin ameliorates reserpine-induced pain-depression dyad: behavioural, biochemi$\mathrm{cal}$, neurochemical and molecular evidences. Psychoneuroendocrinology. 2011;36(10):1570-81.

17. Choudhary KM, Mishra A, Poroikov VV, Goel RK. Ameliorative effect of Curcumin on seizure severity, depression like behavior, learning and memory deficit in post-pentylenetetrazole-kindled mice. Eur J Pharmacol. 2013;704(1-3):33-40.

18. Rinwa P, Kumar A, Garg S. Suppression of neuroinflammatory and apoptotic signaling cascade by curcumin alone and in combination with piperine in rat model of olfactory bulbectomy induced depression. PLoS ONE. 2013;8(4):e61052.

19. Zhao X, Wang C, Zhang JF, Liu L, Liu AM, Ma Q, et al. Chronic curcumin treatment normalizes depression-like behaviors in mice with mononeuropathy: involvement of supraspinal serotonergic system and GABAA receptor. Psychopharmacology. 2014;231(10):2171-87.

20. Lee B, Lee H. Systemic administration of curcumin affect anxiety-related behaviors in a rat model of posttraumatic stress disorder via activation of serotonergic systems. Evid Based Complement Alternat Med. 2018;2018:9041309.

21. Monsey MS, Gerhard DM, Boyle LM, Briones MA, Seligsohn M, Schafe GE. A diet enriched with curcumin impairs newly acquired and reactivated fear memories. Neuropsychopharmacology. 2015;40(5):1278-88.

22. Aubry AV, Khandaker H, Ravenelle R, Grunfeld IS, Bonnefil V, Chan KL, et al. A diet enriched with curcumin promotes resilience to chronic social defeat stress. Neuropsychopharmacology. 2019;44(4):733-42.

23. Afzal A, Batool Z, Sadir S, Liaquat L, Shahzad S, Tabassum S, et al. Therapeutic potential of curcumin in reversing the depression and associated pseudodementia via modulating stress hormone, hippocampal neurotransmitters, and BDNF levels in rats. Neurochem Res. 2021;46(12):3273-85. 
24. Fan C, Song Q, Wang P, Li Y, Yang M, Yu SY. Neuroprotective effects of curcumin on IL-1beta-induced neuronal apoptosis and depression-like behaviors caused by chronic stress in rats. Front Cell Neurosci. 2018;12:516.

25. Zhang WY, Guo YJ, Han WX, Yang MQ, Wen LP, Wang KY, et al. Curcumin relieves depressive-like behaviors via inhibition of the NLRP3 inflammasome and kynurenine pathway in rats suffering from chronic unpredictable mild stress. Int Immunopharmacol. 2019;67:138-44.

26. Xu Y, Ku B, Tie L, Yao H, Jiang W, Ma X, et al. Curcumin reverses the effects of chronic stress on behavior, the HPA axis, BDNF expression and phosphorylation of CREB. Brain Res. 2006;1122(1):56-64.

27. Xu Y, Ku B, Cui L, Li X, Barish PA, Foster TC, et al. Curcumin reverses impaired hippocampal neurogenesis and increases serotonin receptor $1 \mathrm{~A}$ mRNA and brain-derived neurotrophic factor expression in chronically stressed rats. Brain Res. 2007;1162:9-18.

28. Bhutani MK, Bishnoi M, Kulkarni SK. Anti-depressant like effect of curcumin and its combination with piperine in unpredictable chronic stress-induced behavioral, biochemical and neurochemical changes. Pharmacol Biochem Behav. 2009;92(1):39-43.

29. Zhang L, Luo J, Zhang M, Yao W, Ma X, Yu SY. Effects of curcumin on chronic, unpredictable, mild, stress-induced depressive-like behaviour and structural plasticity in the lateral amygdala of rats. Int J Neuropsychopharmacol. 2014;17(5):793-806.

30. Li J, Chen L, Li G, Chen X, Hu S, Zheng L, et al. Sub-acute treatment of curcumin derivative J147 ameliorates depressionlike behavior through 5-HT1A-mediated cAMP signaling. Front Neurosci. 2020;14:701.

31. Xu Y, Ku BS, Yao HY, Lin YH, Ma X, Zhang YH, et al. The effects of curcumin on depressive-like behaviors in mice. Eur $\mathbf{J}$ Pharmacol. 2005;518(1):40-6.

32. Wang R, Xu Y, Wu HL, Li YB, Li YH, Guo JB, et al. The antidepressant effects of curcumin in the forced swimming test involve 5-HT1 and 5-HT2 receptors. Eur J Pharmacol. 2008;578(1):43-50.

33. Kulkarni SK, Bhutani MK, Bishnoi M. Antidepressant activity of curcumin: involvement of serotonin and dopamine system. Psychopharmacology. 2008;201(3):435-42.

34. Zhang L, Xu T, Wang S, Yu L, Liu D, Zhan R, et al. Curcumin produces antidepressant effects via activating MAPK/ERKdependent brain-derived neurotrophic factor expression in the amygdala of mice. Behav Brain Res. 2012;235(1):67-72.

35. Lian L, Xu Y, Zhang J, Yu Y, Zhu N, Guan X, et al. Antidepressant-like effects of a novel curcumin derivative J147: Involvement of 5-HT1A receptor. Neuropharmacology. 2018;135:506-13.

36. Ceremuga TE, Helmrick K, Kufahl Z, Kelley J, Keller B, Philippe F, et al. Investigation of the anxiolytic and antidepressant effects of curcumin, a compound from turmeric (Curcuma longa), in the adult male Sprague-Dawley rat. Holist Nurs Pract. 2017;31(3):193-203.

37. Mei X, Xu D, Xu S, Zheng Y, Xu S. Gastroprotective and antidepressant effects of a new zinc(II)-curcumin complex in rodent models of gastric ulcer and depression induced by stresses. Pharmacol Biochem Behav. 2011;99(1):66-74.

38. Zafir A, Banu N. Antioxidant potential of fluoxetine in comparison to Curcuma longa in restraint-stressed rats. Eur J Pharmacol. 2007;572(1):23-31.

39. Haider S, Naqvi F, Batool Z, Tabassum S, Sadir S, Liaquat $\mathrm{L}$, et al. Pretreatment with curcumin attenuates anxiety while strengthens memory performance after one short stress experience in male rats. Brain Res Bull. 2015;115:1-8.
40. Baker RW, Chothia CH, Pauling P, Petcher TJ. Structure and activity of muscarinic stimulants. Nature. 1971;230(5294):439-45.

41. Zhang L, Ma Z, Wu Z, Jin M, An L, Xue F. Curcumin improves chronic pain induced depression through regulating serum metabolomics in a rat model of trigeminal neuralgia. J Pain Res. 2020;13:3479-92.

42. He X, Yang L, Wang M, Zhuang X, Huang R, Zhu R, et al. Targeting the endocannabinoid/CB1 receptor system for treating major depression through antidepressant activities of curcumin and dexanabinol-loaded solid lipid nanoparticles. Cell Physiol Biochem. 2017;42(6):2281-94.

43. Huang Z, Zhong XM, Li ZY, Feng CR, Pan AJ, Mao QQ. Curcumin reverses corticosterone-induced depressive-like behavior and decrease in brain BDNF levels in rats. Neurosci Lett. 2011;493(3):145-8.

44. He XL, Yang L, Wang ZJ, Huang RQ, Zhu RR, Cheng LM. Solid lipid nanoparticles loading with curcumin and dexanabinol to treat major depressive disorder. Neural Regen Res. 2021;16(3):537-42.

45. He X, Zhu Y, Wang M, Jing G, Zhu R, Wang S. Antidepressant effects of curcumin and HU-211 coencapsulated solid lipid nanoparticles against corticosterone-induced cellular and animal models of major depression. Int J Nanomed. 2016;11:4975-90.

46. Jangra A, Kwatra M, Singh T, Pant R, Kushwah P, Sharma Y, et al. Piperine augments the protective effect of curcumin against lipopolysaccharide-induced neurobehavioral and neurochemical deficits in mice. Inflammation. 2016;39(3):1025-38.

47. Wang Z, Zhang Q, Yuan L, Wang S, Liu L, Yang X, et al. The effects of curcumin on depressive-like behavior in mice after lipopolysaccharide administration. Behav Brain Res. 2014;274:282-90.

48. Vasileva LV, Saracheva KE, Ivanovska MV, Petrova AP, Marchev AS, Georgiev MI, et al. Antidepressant-like effect of salidroside and curcumin on the immunoreactivity of rats subjected to a chronic mild stress model. Food Chem Toxicol. 2018;121:604-11.

49. Mohammad Abu-Taweel G, Al-Fifi Z. Protective effects of curcumin towards anxiety and depression-like behaviors induced mercury chloride. Saudi J Biol Sci. 2021;28(1):125-34.

50. Wang R, Li YB, Li YH, Xu Y, Wu HL, Li XJ. Curcumin protects against glutamate excitotoxicity in rat cerebral cortical neurons by increasing brain-derived neurotrophic factor level and activating TrkB. Brain Res. 2008;1210:84-91.

51. Madiha S, Haider S. Curcumin restores rotenone induced depressive-like symptoms in animal model of neurotoxicity: assessment by social interaction test and sucrose preference test. Metab Brain Dis. 2019;34(1):297-308.

52. Yohn SE, Gorka D, Mistry A, Collins S, Qian E, Correa M, et al. Oral ingestion and intraventricular injection of curcumin attenuates the effort-related effects of the VMAT-2 inhibitor tetrabenazine: implications for motivational symptoms of depression. $\mathrm{J}$ Nat Prod. 2017;80(10):2839-44.

53. Demir EA, Oz M, Alp MI, Gergerlioglu HS, Nurullahoglu KE, Yerlikaya FH. Co-administration of cisplatin and curcumin does not alter mood-associated behaviors. Bratisl Lek Listy. 2016;117(2):106-11.

54. Fidelis EM, Savall ASP, da Luz AE, Carvalho F, Teixeira FEG, Haas SE, et al. Curcumin-loaded nanocapsules reverses the depressant-like behavior and oxidative stress induced by betaamyloid in mice. Neuroscience. 2019;15(423):122-30.

55. Saied NM, Georgy GS, Hussien RM, Hassan WA. Neuromodulatory effect of curcumin on catecholamine systems and inflammatory cytokines in ovariectomized female rats. Clin Exp Pharmacol Physiol. 2021;48(3):337-46. 
56. Chang XR, Wang L, Li J, Wu DS. Analysis of anti-depressant potential of curcumin against depression induced male albino wistar rats. Brain Res. 2016;1642:219-25.

57. Xu Y, Ku BS, Yao HY, Lin YH, Ma X, Zhang YH, et al. Antidepressant effects of curcumin in the forced swim test and olfactory bulbectomy models of depression in rats. Pharmacol Biochem Behav. 2005;82(1):200-6.

58. Morales-Medina JC, Iannitti T, Freeman A, Caldwell HK. The olfactory bulbectomized rat as a model of depression: the hippocampal pathway. Behav Brain Res. 2017;317:562-75.

59. Bergman J, Miodownik C, Bersudsky Y, Sokolik S, Lerner PP, Kreinin A, et al. Curcumin as an add-on to antidepressive treatment: a randomized, double-blind, placebo-controlled, pilot clinical study. Clin Neuropharmacol. 2013;36(3):73-7.

60. Yu JJ, Pei LB, Zhang Y, Wen ZY, Yang JL. Chronic supplementation of curcumin enhances the efficacy of antidepressants in major depressive disorder: a randomized, doubleblind, placebo-controlled pilot study. J Clin Psychopharmacol. 2015;35(4):406-10.

61. Kanchanatawan B, Tangwongchai S, Sughondhabhirom A, Suppapitiporn S, Hemrunrojn S, Carvalho AF, et al. Add-on treatment with curcumin has antidepressive effects in thai patients with major depression: results of a randomized double-blind placebo-controlled study. Neurotox Res. 2018;33(3):621-33.

62. Lopresti AL, Maes M, Hood SD, Maker GL, Drummond PD. Curcumin for the treatment of major depression: a randomised, double-blind, placebo controlled study. J Affect Disord. 2014;167:368-75.

63. Sanmukhani J, Satodia V, Trivedi J, Patel T, Tiwari D, Panchal B, et al. Efficacy and safety of curcumin in major depressive disorder: a randomized controlled trial. Phytother Res. 2014;28(4):579-85.

64. Panahi Y, Badeli R, Karami GR, Sahebkar A. Investigation of the efficacy of adjunctive therapy with bioavailability-boosted curcuminoids in major depressive disorder. Phytother Res. 2015;29(1):17-21.

65. Lopresti AL, Drummond PD. Efficacy of curcumin, and a saffron/ curcumin combination for the treatment of major depression: a randomised, double-blind, placebo-controlled study. J Affect Disord. 2017;207:188-96.

66. Panahi Y, Hosseini MS, Khalili N, Naimi E, Soflaei SS, Majeed $\mathrm{M}$, et al. Effects of supplementation with curcumin on serum adipokine concentrations: a randomized controlled trial. Nutrition. 2016;32(10):1116-22.

67. Anderson G, Berk M, Dodd S, Bechter K, Altamura AC, Dell'osso B, et al. Editorial: immuno-inflammatory, oxidative and nitrosative stress, and neuroprogressive pathways in the etiology, course and treatment of schizophrenia. Prog Neuropsychopharmacol Biol Psychiatry. 2013;42:1-4.

68. Wang Z, Zhang Q, Huang H, Liu Z. The efficacy and acceptability of curcumin for the treatment of depression or depressive symptoms: A systematic review and meta-analysis. J Affect Disord. 2021;282:242-51.

69. Fusar-Poli L, Vozza L, Gabbiadini A, Vanella A, Concas I, Tinacci S, et al. Curcumin for depression: a meta-analysis. Crit Rev Food Sci Nutr. 2020;60(15):2643-53.

70. Al-Karawi D, Al Mamoori DA, Tayyar Y. The role of curcumin administration in patients with major depressive disorder: mini meta-analysis of clinical trials. Phytother Res. 2015;30(2):175-83.

71. Cox KH, Pipingas A, Scholey AB. Investigation of the effects of solid lipid curcumin on cognition and mood in a healthy older population. J Psychopharmacol. 2015;29(5):642-51.

72. Esmaily H, Sahebkar A, Iranshahi M, Ganjali S, Mohammadi A, Ferns G, et al. An investigation of the effects of curcumin on anxiety and depression in obese individuals: a randomized controlled trial. Chin J Integr Med. 2015;21(5):332-8.

73. Kuszewski JC, Howe PRC, Wong RHX. An exploratory analysis of changes in mental wellbeing following curcumin and fish oil supplementation in middle-aged and older adults. Nutrients. 2020;12(10):2902.

74. Latif R, Mumtaz S, Al Sheikh MH, Chathoth S, Nasser Al Naimi S. Effects of turmeric on cardiovascular risk factors, mental health, and serum homocysteine in overweight, obese females. Altern Ther Health Med. 2021;27(Suppl 1):114-9.

75. Fanaei H, Khayat S, Kasaeian A, Javadimehr M. Effect of curcumin on serum brain-derived neurotrophic factor levels in women with premenstrual syndrome: A randomized, doubleblind, placebo-controlled trial. Neuropeptides. 2016;56:25-31.

76. Asadi S, Gholami MS, Siassi F, Qorbani M, Sotoudeh G. Beneficial effects of nano-curcumin supplement on depression and anxiety in diabetic patients with peripheral neuropathy: a randomized, double-blind, placebo-controlled clinical trial. Phytother Res. 2020;34(4):896-903.

77. Lopresti AL, Smith SJ, Rea A, Michel S. Efficacy of a curcumin extract (Curcugen) on gastrointestinal symptoms and intestinal microbiota in adults with self-reported digestive complaints: a randomised, double-blind, placebo-controlled study. BMC Complement Med Ther. 2021;21(1):40.

78. Ma T, Ma Z, Zhang X, Zhou F. Evaluation of effect of curcumin on psychological state of patients with pulmonary hypertension by magnetic resonance image under deep learning. Contrast Media Mol Imaging. 2021;2021:9935754.

79. Lopresti AL, Maker GL, Hood SD, Drummond PD. A review of peripheral biomarkers in major depression: The potential of inflammatory and oxidative stress biomarkers. Prog Neuropsychopharmacol Biol Psychiatry. 2014;48:102-11.

80. Kaltenboeck A, Harmer C. The neuroscience of depressive disorders: a brief review of the past and some considerations about the future. Brain Neurosci Adv. 2018;2:2398212818799269.

81. Moriguchi S, Takamiya A, Noda Y, Horita N, Wada M, Tsugawa $\mathrm{S}$, et al. Glutamatergic neurometabolite levels in major depressive disorder: a systematic review and meta-analysis of proton magnetic resonance spectroscopy studies. Mol Psychiatry. 2019;24(7):952-64.

82. Kumar TP, Antony S, Gireesh G, George N, Paulose CS. Curcumin modulates dopaminergic receptor, CREB and phospholipase $\mathrm{C}$ gene expression in the cerebral cortex and cerebellum of streptozotocin induced diabetic rats. J Biomed Sci. 2010;17:43.

83. Ramkumar M, Rajasankar S, Gobi VV, Janakiraman U, Manivasagam T, Thenmozhi AJ, et al. Demethoxycurcumin, a Natural derivative of curcumin abrogates rotenone-induced dopamine depletion and motor deficits by its antioxidative and anti-inflammatory properties in parkinsonian Rats. Pharmacogn Mag. 2018;14(53):9-16.

84. Alam M, Schmidt WJ. Rotenone destroys dopaminergic neurons and induces parkinsonian symptoms in rats. Behav Brain Res. 2002;136(1):317-24.

85. Afshari AR, Fanoudi S, Rajabian A, Sadeghnia HR, Mollazadeh $\mathrm{H}$, Hosseini A. Potential protective roles of phytochemicals on glutamate-induced neurotoxicity: a review. Iran J Basic Med Sci. 2020;23(9):1113-23.

86. Park CH, Song JH, Kim SN, Lee JH, Lee HJ, Kang KS, et al. Neuroprotective effects of tetrahydrocurcumin against glutamateinduced oxidative stress in hippocampal HT22 cells. Molecules. 2019;25(1):144.

87. Chen K, An Y, Tie L, Pan Y, Li X. Curcumin protects neurons from glutamate-induced excitotoxicity by membrane anchored AKAP79-PKA interaction network. Evid Based Complement Alternat Med. 2015;2015:706207. 
88. Matteucci A, Cammarota R, Paradisi S, Varano M, Balduzzi M, Leo L, et al. Curcumin protects against NMDA-induced toxicity: a possible role for NR2A subunit. Invest Ophthalmol Vis Sci. 2011;52(2):1070-7.

89. Enache D, Pariante CM, Mondelli V. Markers of central inflammation in major depressive disorder: a systematic review and meta-analysis of studies examining cerebrospinal fluid, positron emission tomography and post-mortem brain tissue. Brain Behav Immun. 2019;81:24-40.

90. Osimo EF, Pillinger T, Rodriguez IM, Khandaker GM, Pariante $\mathrm{CM}$, Howes OD. Inflammatory markers in depression: a metaanalysis of mean differences and variability in 5,166 patients and 5,083 controls. Brain Behav Immun. 2020;87:901-9.

91. Osimo EF, Baxter LJ, Lewis G, Jones PB, Khandaker GM. Prevalence of low-grade inflammation in depression: a systematic review and meta-analysis of CRP levels. Psychol Med. 2019;49(12):1958-70.

92. Hunt C, Macedo ECT, Suchting R, de Dios C, Cuellar Leal VA, Soares JC, et al. Effect of immune activation on the kynurenine pathway and depression symptoms - a systematic review and meta-analysis. Neurosci Biobehav Rev. 2020;118:514-23.

93. Chen X, Pu J, Liu Y, Tian L, Chen Y, Gui S, et al. Increased $\mathrm{C}$-reactive protein concentrations were associated with suicidal behavior in patients with depressive disorders: a meta-analysis. Psychiatry Res. 2020;292:1320.

94. Almeida IB, Gomes IA, Shanmugam S, de Moura TR, Magalhaes LS, de Aquino LAG, et al. Inflammatory modulation of fluoxetine use in patients with depression: a systematic review and meta-analysis. Cytokine. 2020;131:155100.

95. Dionisie V, Filip GA, Manea MC, Manea M, Riga S. The antiinflammatory role of SSRI and SNRI in the treatment of depression: a review of human and rodent research studies. Inflammopharmacology. 2021;29(1):75-90.

96. Tabrizi R, Vakili S, Akbari M, Mirhosseini N, Lankarani KB, Rahimi M, et al. The effects of curcumin-containing supplements on biomarkers of inflammation and oxidative stress: A systematic review and meta-analysis of randomized controlled trials. Phytother Res. 2019;33(2):253-62.

97. Jiang H, Wang Z, Wang Y, Xie K, Zhang Q, Luan Q, et al. Antidepressant-like effects of curcumin in chronic mild stress of rats: involvement of its anti-inflammatory action. Prog Neuropsychopharmacol Biol Psychiatry. 2013;47:33-9.

98. Wigner P, Czarny P, Galecki P, Sliwinski T. Oxidative and nitrosative stress as well as the tryptophan catabolites pathway in depressive disorders. Psychiatr Danub. 2017;29(4):394-400.

99. Wigner P, Czarny P, Galecki P, Su KP, Sliwinski T. The molecular aspects of oxidative \& nitrosative stress and the tryptophan catabolites pathway (TRYCATs) as potential causes of depression. Psychiatry Res. 2018;262:566-74.

100. Benameur T, Soleti R, Panaro MA, La Torre ME, Monda V, Messina $\mathrm{G}$, et al. Curcumin as prospective anti-aging natural compound: focus on brain. Molecules. 2021;26(16):4794.

101. Abrahams S, Haylett WL, Johnson G, Carr JA, Bardien S. Antioxidant effects of curcumin in models of neurodegeneration, aging, oxidative and nitrosative stress: a review. Neuroscience. 2019;406:1-21

102. Longobardi C, Damiano S, Andretta E, Prisco F, Russo V, Pagnini F, et al. Curcumin modulates nitrosative stress, inflammation, and DNA damage and protects against ochratoxin a-induced hepatotoxicity and nephrotoxicity in rats. Antioxidants (Basel). 2021;10(8):1239.

103. Jarhahzadeh M, Alavinejad P, Farsi F, Husain D, Rezazadeh A. The effect of turmeric on lipid profile, malondialdehyde, liver echogenicity and enzymes among patients with nonalcoholic fatty liver disease: a randomized double blind clinical trial. Diabetol Metab Syndr. 2021;13(1):112.
104. Salehi M, Mashhadi NS, Esfahani PS, Feizi A, Hadi A, Askari G. The effects of curcumin supplementation on muscle damage, oxidative stress, and inflammatory markers in healthy females with moderate physical activity: a randomized, double-blind, placebo-controlled clinical trial. Int J Prev Med. 2021;12:94.

105. Rodrigues HCN, Martins TFP, Santana N, Braga CC, Silva MAC, Cunha LCD, et al. Antioxidant and anti-inflammatory response to curcumin supplementation in hemodialysis patients: a randomized, double-blind, placebo-controlled clinical trial. Clin Nutr ESPEN. 2021;44:136-42.

106. Shafabakhsh R, Mobini M, Raygan F, Aghadavod E, Ostadmohammadi V, Amirani E, et al. Curcumin administration and the effects on psychological status and markers of inflammation and oxidative damage in patients with type 2 diabetes and coronary heart disease. Clin Nutr ESPEN. 2020;40:77-82.

107. Jakubczyk K, Druzga A, Katarzyna J, Skonieczna-Zydecka K. Antioxidant potential of curcumin-a meta-analysis of randomized clinical trials. Antioxidants (Basel). 2020;9(11):1092.

108. Nandam LS, Brazel M, Zhou M, Jhaveri DJ. Cortisol and major depressive disorder-translating findings from humans to animal models and back. Front Psychiatry. 2019;10:974.

109. Keller J, Gomez R, Williams G, Lembke A, Lazzeroni L, Murphy GM Jr, et al. HPA axis in major depression: cortisol, clinical symptomatology and genetic variation predict cognition. Mol Psychiatry. 2017;22(4):527-36.

110. Juruena MF, Bocharova M, Agustini B, Young AH. Atypical depression and non-atypical depression: Is HPA axis function a biomarker? A systematic review. J Affect Disord. 2018;233:45-67.

111. Enyeart JA, Liu H, Enyeart JJ. Curcumin inhibits ACTH- and angiotensin II-stimulated cortisol secretion and $\mathrm{Ca}(\mathrm{v}) 3.2$ current. J Nat Prod. 2009;72(8):1533-7.

112. Lin $\mathrm{H}, \mathrm{Hu}$ GX, Guo J, Ge Y, Liang G, Lian QQ, et al. Mono-carbonyl curcumin analogues as 11 beta-hydroxysteroid dehydrogenase 1 inhibitors. Bioorg Med Chem Lett. 2013;23(15):4362-6.

113. Yuan X, Li H, Bai H, Su Z, Xiang Q, Wang C, et al. Synthesis of novel curcumin analogues for inhibition of 11beta-hydroxysteroid dehydrogenase type 1 with anti-diabetic properties. Eur J Med Chem. 2014;77:223-30.

114. Hu GX, Lin H, Lian QQ, Zhou SH, Guo J, Zhou HY, et al. Curcumin as a potent and selective inhibitor of 11 beta-hydroxysteroid dehydrogenase 1: improving lipid profiles in high-fat-diettreated rats. PLoS ONE. 2013;8(3):e49976.

115. Ma XX, Liu J, Wang CM, Zhou JP, He ZZ, Lin H. Low-dose curcumin stimulates proliferation of rat embryonic neural stem cells through glucocorticoid receptor and STAT3. CNS Neurosci Ther. 2018;24(10):940-6.

116. Lopresti AL, Maes M, Meddens MJ, Maker GL, Arnoldussen E, Drummond PD. Curcumin and major depression: a randomised, double-blind, placebo-controlled trial investigating the potential of peripheral biomarkers to predict treatment response and antidepressant mechanisms of change. Eur Neuropsychopharmacol. 2015;25(1):38-50.

117. Cicero AFG, Sahebkar A, Fogacci F, Bove M, Giovannini M, Borghi C. Effects of phytosomal curcumin on anthropometric parameters, insulin resistance, cortisolemia and non-alcoholic fatty liver disease indices: a double-blind, placebo-controlled clinical trial. Eur J Nutr. 2020;59(2):477-83.

118. Persidsky Y, Ramirez SH, Haorah J, Kanmogne GD. Bloodbrain barrier: structural components and function under physiologic and pathologic conditions. J Neuroimmune Pharmacol. 2006;1(3):223-36.

119. Kealy J, Greene C, Campbell M. Blood-brain barrier regulation in psychiatric disorders. Neurosci Lett. 2020;726:133664. 
120. Morris G, Fernandes BS, Puri BK, Walker AJ, Carvalho AF, Berk M. Leaky brain in neurological and psychiatric disorders: Drivers and consequences. Aust N Z J Psychiatry. 2018;52(10):924-48.

121. Welcome MO, Mastorakis NE. Stress-induced blood brain barrier disruption: Molecular mechanisms and signaling pathways. Pharmacol Res. 2020;157:104769.

122. Wu S, Guo T, Qi W, Li Y, Gu J, Liu C, et al. Curcumin ameliorates ischemic stroke injury in rats by protecting the integrity of the blood-brain barrier. Exp Ther Med. 2021;22(1):783.

123. Wang Y, Luo J, Li SY. Nano-curcumin simultaneously protects the blood-brain barrier and reduces M1 microglial activation during cerebral ischemia-reperfusion injury. ACS Appl Mater Interfaces. 2019;11(4):3763-70.

124. Yuan J, Liu W, Zhu H, Zhang X, Feng Y, Chen Y, et al. Curcumin attenuates blood-brain barrier disruption after subarachnoid hemorrhage in mice. J Surg Res. 2017;207:85-91.

125. Wang YF, Gu YT, Qin GH, Zhong L, Meng YN. Curcumin ameliorates the permeability of the blood-brain barrier during hypoxia by upregulating heme oxygenase- 1 expression in brain microvascular endothelial cells. J Mol Neurosci. 2013;51(2):344-51.

126. Gibon J, Barker PA. Neurotrophins and proneurotrophins: Focus on Synaptic Activity and Plasticity in the Brain. Neuroscientist. 2017;23(6):587-604.

127. Mosiolek A, Mosiolek J, Jakima S, Pieta A, Szulc A. Effects of antidepressant treatment on neurotrophic factors (BDNF and IGF-1) in patients with major depressive disorder (MDD). J Clin Med. 2021;10(15):3377.

128. Castren E, Monteggia LM. Brain-derived neurotrophic factor signaling in depression and antidepressant action. Biol Psychiatry. 2021;90(2):128-36.

129. Choi GY, Kim HB, Hwang ES, Lee S, Kim MJ, Choi JY, et al. Curcumin alters neural plasticity and viability of intact hippocampal circuits and attenuates behavioral despair and cox-2 expression in chronically stressed rats. Mediators Inflamm. 2017;2017:6280925.

130. Liu D, Wang Z, Gao Z, Xie K, Zhang Q, Jiang H, et al. Effects of curcumin on learning and memory deficits, BDNF, and ERK protein expression in rats exposed to chronic unpredictable stress. Behav Brain Res. 2014;271:116-21.

131. Sarraf P, Parohan M, Javanbakht MH, Ranji-Burachaloo S, Djalali M. Short-term curcumin supplementation enhances serum brain-derived neurotrophic factor in adult men and women: a systematic review and dose-response meta-analysis of randomized controlled trials. Nutr Res. 2019;69:1-8.

132. Sofroniew MV, Vinters HV. Astrocytes: biology and pathology. Acta Neuropathol. 2010;119(1):7-35.

133. Zhou X, Xiao Q, Xie L, Yang F, Wang L, Tu J. Astrocyte, a promising target for mood disorder interventions. Front Mol Neurosci. 2019;12:136.

134. O'Leary LA, Mechawar N. Implication of cerebral astrocytes in major depression: a review of fine neuroanatomical evidence in humans. Glia. 2021;69(9):2077-99.

135. Daverey A, Agrawal SK. Curcumin alleviates oxidative stress and mitochondrial dysfunction in astrocytes. Neuroscience. 2016;333:92-103.

136. Daverey A, Agrawal SK. Pre and post treatment with curcumin and resveratrol protects astrocytes after oxidative stress. Brain Res. 2018;1692:45-55.

137. Mohammadi A, Hosseinzadeh Colagar A, Khorshidian A, Amini $\mathrm{SM}$. The functional roles of curcumin on astrocytes in neurodegenerative diseases. NeuroImmunoModulation. 2022;29(1):4-14.

138. Eghbaliferiz S, Farhadi F, Barreto GE, Majeed M, Sahebkar A. Effects of curcumin on neurological diseases: focus on astrocytes. Pharmacol Rep. 2020;72(4):769-82.
139. Singhal G, Baune BT. Microglia: an interface between the loss of neuroplasticity and depression. Front Cell Neurosci. 2017;11:270.

140. Lugo-Huitron R, Ugalde Muniz P, Pineda B, Pedraza-Chaverri J, Rios C, Perez-de la Cruz V. Quinolinic acid: an endogenous neurotoxin with multiple targets. Oxid Med Cell Longev. 2013;2013:104024.

141. Brites D, Fernandes A. Neuroinflammation and depression: microglia activation, extracellular microvesicles and microRNA dysregulation. Front Cell Neurosci. 2015;9:476.

142. Ghasemi F, Bagheri H, Barreto GE, Read MI, Sahebkar A. Effects of curcumin on microglial cells. Neurotox Res. 2019;36(1):12-26.

143. Gao Y, Zhuang Z, Lu Y, Tao T, Zhou Y, Liu G, et al. Curcumin mitigates neuro-inflammation by modulating microglia polarization through inhibiting TLR4 axis signaling pathway following experimental subarachnoid hemorrhage. Front Neurosci. 2019;13:1223

144. Singh S, Kumar P. Neuroprotective activity of curcumin in combination with piperine against quinolinic acid induced neurodegeneration in rats. Pharmacology. 2016;97(3-4):151-60.

145. Santana-Martinez RA, Silva-Islas CA, Fernandez-Orihuela YY, Barrera-Oviedo D, Pedraza-Chaverri J, HernandezPando R, et al. The therapeutic effect of curcumin in quinolinic acid-induced neurotoxicity in rats is associated with BDNF, ERK1/2, Nrf2, and antioxidant enzymes. Antioxidants (Basel). 2019;8(9):388

146. Gimenez-Palomo A, Dodd S, Anmella G, Carvalho AF, Scaini $\mathrm{G}$, Quevedo J, et al. The role of mitochondria in mood disorders: from physiology to pathophysiology and to treatment. Front Psychiatry. 2021;12:546801.

147. Glombik K, Budziszewska B, Basta-Kaim A. Mitochondriatargeting therapeutic strategies in the treatment of depression. Mitochondrion. 2021;58:169-78.

148. Tripathi A, Scaini G, Barichello T, Quevedo J, Pillai A. Mitophagy in depression: Pathophysiology and treatment targets. Mitochondrion. 2021;61:1-10.

149. Rappeneau V, Wilmes L, Touma C. Molecular correlates of mitochondrial dysfunctions in major depression: evidence from clinical and rodent studies. Mol Cell Neurosci. 2020;109:103555.

150. Kandezi N, Mohammadi M, Ghaffari M, Gholami M, Motaghinejad M, Safari S. Novel Insight to Neuroprotective Potential of Curcumin: A Mechanistic Review of Possible Involvement of Mitochondrial Biogenesis and PI3/Akt/ GSK3 or PI3/Akt/CREB/ BDNF Signaling Pathways. Int J Mol Cell Med. 2020;9(1):1-32.

151. Mursaleen L, Somavarapu S, Zariwala MG. Deferoxamine and curcumin loaded nanocarriers protect against rotenone-induced neurotoxicity. J Parkinsons Dis. 2020;10(1):99-111.

152. Jia N, Sun Q, Su Q, Chen G. SIRT1-mediated deacetylation of PGC1alpha attributes to the protection of curcumin against glutamate excitotoxicity in cortical neurons. Biochem Biophys Res Commun. 2016;478(3):1376-81.

153. Subedi L, Gaire BP. Neuroprotective effects of curcumin in cerebral ischemia: cellular and molecular mechanisms. ACS Chem Neurosci. 2021;12(14):2562-72.

154. Ryskalin L, Puglisi-Allegra S, Lazzeri G, Biagioni F, Busceti CL, Balestrini L, et al. Neuroprotective effects of curcumin in methamphetamine-induced toxicity. Molecules. 2021;26(9):2493.

155. Guzel M, Naziroglu M, Akpinar O, Cinar R. Interferon gammamediated oxidative stress induces apoptosis, neuroinflammation, zinc ion influx, and TRPM2 channel activation in neuronal cell line: modulator role of curcumin. Inflammation. 2021;44(5):1878-94. 
156. Bagheri H, Ghasemi F, Barreto GE, Rafiee R, Sathyapalan T, Sahebkar A. Effects of curcumin on mitochondria in neurodegenerative diseases. BioFactors. 2020;46(1):5-20.

157. Kunugi $\mathrm{H}$. gut microbiota and pathophysiology of depressive disorder. Ann Nutr Metab. 2021;77(Suppl 2):11-20.

158. Rudzki L, Maes M. From, "Leaky Gut" to impaired glianeuron communication in depression. Adv Exp Med Biol. 2021;1305:129-55.

159. Liu L, Zhu G. Gut-brain axis and mood disorder. Front Psychiatry. 2018;9:223.

160. Misera A, Liskiewicz P, Loniewski I, Skonieczna-Zydecka K, Samochowiec J. Effect of psychobiotics on psychometric tests and inflammatory markers in major depressive disorder: metaanalysis of randomized controlled trials with meta-regression. Pharmaceuticals (Basel). 2021;14(10):952.

161. Lopresti AL. The problem of curcumin and its bioavailability: could its gastrointestinal influence contribute to its overall healthenhancing effects? Adv Nutr. 2018;9(1):41-50.

162. Lobo de Sa FD, Butkevych E, Nattramilarasu PK, Fromm A, Mousavi S, Moos V, et al. Curcumin mitigates immune-induced epithelial barrier dysfunction by Campylobacter jejuni. Int J Mol Sci. 2019;20(19):4830.

163. Feng D, Zou J, Su D, Mai H, Zhang S, Li P, et al. Curcumin prevents high-fat diet-induced hepatic steatosis in $\operatorname{ApoE}(-/-)$ mice by improving intestinal barrier function and reducing endotoxin and liver TLR4/NF-kappaB inflammation. Nutr Metab (Lond). 2019;16:79.

164. Szymanski MC, Gillum TL, Gould LM, Morin DS, Kuennen MR. Short-term dietary curcumin supplementation reduces gastrointestinal barrier damage and physiological strain responses during exertional heat stress. J Appl Physiol (1985). 2018;124(2):330-40.

165. Islam T, Koboziev I, Albracht-Schulte K, Mistretta B, Scoggin S, Yosofvand $\mathrm{M}$, et al. Curcumin reduces adipose tissue inflammation and alters gut microbiota in diet-induced obese male mice. Mol Nutr Food Res. 2021;65:e2100274.

166. Xu X, Wang H, Guo D, Man X, Liu J, Li J, et al. Curcumin modulates gut microbiota and improves renal function in rats with uric acid nephropathy. Ren Fail. 2021;43(1):1063-75.

167. Wu Y, Chen Y, Li Q, Ye X, Guo X, Sun L, et al. Tetrahydrocurcumin alleviates allergic airway inflammation in asthmatic mice by modulating the gut microbiota. Food Funct. 2021;12(15):6830-40.

168. Ge T, Fan J, Yang W, Cui R, Li B. Leptin in depression: a potential therapeutic target. Cell Death Dis. 2018;9(11):1096.

169. Lu XY. The leptin hypothesis of depression: a potential link between mood disorders and obesity? Curr Opin Pharmacol. 2007;7(6):648-52.

170. Cernea S, Both E, Hutanu A, Sular FL, Roiban AL. Correlations of serum leptin and leptin resistance with depression and anxiety in patients with type 2 diabetes. Psychiatry Clin Neurosci. 2019;73(12):745-53.

171. Cakici N, Bot M, Lamers F, Janssen T, van der Spek PJ, de Haan L, et al. Increased serum levels of leptin and insulin in both schizophrenia and major depressive disorder: A crossdisorder proteomics analysis. Eur Neuropsychopharmacol. 2019;29(7):835-46.

172. Atkin SL, Katsiki N, Derosa G, Maffioli P, Sahebkar A. Curcuminoids lower plasma leptin concentrations: a meta-analysis. Phytother Res. 2017;31(12):1836-41.

173. Martin H, Bullich S, Guiard BP, Fioramonti X. The impact of insulin on the serotonergic system and consequences on diabetes-associated mood disorders. J Neuroendocrinol. 2021;33(4):e12928.
174. Woo YS, Lim HK, Wang SM, Bahk WM. Clinical Evidence of antidepressant effects of insulin and anti-hyperglycemic agents and implications for the pathophysiology of depression-a literature review. Int J Mol Sci. 2020;21(18):6969.

175. Zhang T, He Q, Liu Y, Chen Z, Hu H. Efficacy and safety of curcumin supplement on improvement of insulin resistance in people with type 2 diabetes mellitus: a systematic review and meta-analysis of randomized controlled trials. Evid Based Complement Alternat Med. 2021;2021:4471944.

176. Lowe H, Toyang N, Steele B, Bryant J, Ngwa W. The endocannabinoid system: a potential target for the treatment of various diseases. Int J Mol Sci. 2021;22(17):9472.

177. Yarar E. Role and function of endocannabinoid system in major depressive disease. Med Cannabis Cannabinoids. 2021;4(1):1-12.

178. Graczyk M, Lukowicz M, Dzierzanowski T. Prospects for the use of cannabinoids in psychiatric disorders. Front Psychiatry. 2021;12:620073.

179. Hassanzadeh $P$, Hassanzadeh $A$. The $C B(1)$ receptor-mediated endocannabinoid signaling and NGF: the novel targets of curcumin. Neurochem Res. 2012;37(5):1112-20.

180. Zarrouf FA, Artz S, Griffith J, Sirbu C, Kommor M. Testosterone and depression: systematic review and meta-analysis. J Psychiatr Pract. 2009;15(4):289-305.

181. Hwang WJ, Lee TY, Kim NS, Kwon JS. The role of estrogen receptors and their signaling across psychiatric disorders. Int J Mol Sci. 2020;22(1):373.

182. Mohajeri M, Bianconi V, Avila-Rodriguez MF, Barreto GE, Jamialahmadi T, Pirro M, et al. Curcumin: a phytochemical modulator of estrogens and androgens in tumors of the reproductive system. Pharmacol Res. 2020;156:104765.

183. Hallman K, Aleck K, Dwyer B, Lloyd V, Quigley M, Sitto N, et al. The effects of turmeric (curcumin) on tumor suppressor protein (p53) and estrogen receptor (ERalpha) in breast cancer cells. Breast Cancer (Dove Med Press). 2017;9:153-61.

184. Elsedawi BF, Hussein Y, Sabry MA, Aziz JA. Effect of fluoxetine on the testes of adult albino rats and the possible protective role of curcumin. Anat Sci Int. 2021;96(2):187-96.

185. Cheng Y, Yang Y, Wu Y, Wang W, Xiao L, Zhang Y, et al. The curcumin derivative, H10, suppresses hormone-dependent prostate cancer by inhibiting 17beta-hydroxysteroid dehydrogenase type 3. Front Pharmacol. 2020;11:637.

186. Grosso G, Micek A, Marventano S, Castellano S, Mistretta A, Pajak A, et al. Dietary n-3 PUFA, fish consumption and depression: a systematic review and meta-analysis of observational studies. J Affect Disord. 2016;205:269-81.

187. von Schacky C. Importance of EPA and DHA blood levels in brain structure and function. Nutrients. 2021;13(4):1074.

188. Wu A, Noble EE, Tyagi E, Ying Z, Zhuang Y, Gomez-Pinilla F. Curcumin boosts DHA in the brain: Implications for the prevention of anxiety disorders. Biochim Biophys Acta. 2015;1852(5):951-61.

189. Namgyal D, Chandan K, Ali S, Ahmad A, Hashim MJ, Sarwat M. Aberrant lighting causes anxiety-like behavior in mice but curcumin ameliorates the symptoms. Animals (Basel). 2021;11(9):2590.

190. Kukkemane K, Jagota A. Therapeutic effects of curcumin on age-induced alterations in daily rhythms of clock genes and Sirt1 expression in the SCN of male Wistar rats. Biogerontology. 2019;20(4):405-19.

191. Thummadi NB, Jagota A. Aging renders desynchronization between clock and immune genes in male Wistar rat kidney: chronobiotic role of curcumin. Biogerontology. 2019;20(4):515-32. 
192. Lamont EW, Legault-Coutu D, Cermakian N, Boivin DB. The role of circadian clock genes in mental disorders. Dialogues Clin Neurosci. 2007;9(3):333-42.

193. Bunney BG, Li JZ, Walsh DM, Stein R, Vawter MP, Cartagena $\mathrm{P}$, et al. Circadian dysregulation of clock genes: clues to rapid treatments in major depressive disorder. Mol Psychiatry. 2015;20(1):48-55.

194. Liu Z, Huang M, Wu X, Shi G, Xing L, Dong Z, et al. PER1 phosphorylation specifies feeding rhythm in mice. Cell Rep. 2014;7(5):1509-20.

195. Turek FW. From circadian rhythms to clock genes in depression. Int Clin Psychopharmacol. 2007;22(Suppl 2):S1-8.

196. US Food and Drug Administration. GRAS Notices [cited $10 \mathrm{Jan}$ 2022]. https://www.cfsanappsexternal.fda.gov/scripts/fdcc/?set= GRASNotices. Accessed 10 Jan 2022.

197. Hewlings SJ, Kalman DS. Curcumin: a review of its effects on human health. Foods. 2017;6(10):92.
198. Kim DC, Ku SK, Bae JS. Anticoagulant activities of curcumin and its derivative. BMB Rep. 2012;45(4):221-6.

199. Sharma RA, Steward WP, Gescher AJ. Pharmacokinetics and pharmacodynamics of curcumin. Adv Exp Med Biol. 2007;595:453-70.

200. Smeets T, Cornelisse S, Quaedflieg CW, Meyer T, Jelicic M, Merckelbach H. Introducing the Maastricht Acute Stress Test (MAST): a quick and non-invasive approach to elicit robust autonomic and glucocorticoid stress responses. Psychoneuroendocrinology. 2012;37(12):1998-2008.

201. Allen AP, Kennedy PJ, Cryan JF, Dinan TG, Clarke G. Biological and psychological markers of stress in humans: focus on the Trier Social Stress Test. Neurosci Biobehav Rev. 2014;38:94-124. 